\title{
Inhibitory Effectiveness of Musk on Viability of Protoscolices of Hydatid Cysts
}

\author{
Kamil M. M. AL-Jobori ${ }^{1 *}$, Azhar Ali Faraj ${ }^{2}$ and Noor M. Witwit ${ }^{1}$ \\ ${ }^{1}$ Institute of Genetic Engineering and Biotechnology for Post Graduate Studies, \\ University of Baghdad, Iraq \\ ${ }^{2}$ College of Veterinary Medicine, University of Baghdad, Iraq \\ *Corresponding author
}

\begin{abstract}
A B S T R A C T
Keywords

Musk on Viability,

Protoscolices,

Hydatid Cysts,

zoonotic

diseases,

Echinococcus

granulosus

Article Info

Accepted:

22 March 2016

Available Online:

10 April 2016

Hydatid disease is considered as one of the important zoonotic diseases, due to the complications and the difficulties of the diagnosis and treatment. The present work evaluates the effect of musk concentrations on the viability of Echinococcus granulosus protoscoleces in vitro. Three different concentrations of musk 25, 50 and $100 \%$ were used, in addition to control for 10, 20, 30, 40, 50 and $60 \mathrm{~min}$. While the rate of dead protoscolices was $6.98 \%$ in the control group, when protoscolices were exposed to musk concentration of $25 \%$, the rate of dead protoscolices increased to $21.44,34.20,43.00,51.40,79.34$ and $100 \%$ after 10 , $20,30,40,50$ and 60 minutes, respectively. The mortality rate of protoscolices increased to $53.93,81.36,97.04$ and $100 \%$ when they were exposed to the concentration of $50 \%$ after $10,20,30$, and $40 \mathrm{~min}$, respectively. One hundred percent mortality rate was observed at concentration of $100 \%$ after $30 \mathrm{~min}$ of exposure. This in vitro study showed that musk can be a promising source of potent antiprotoscolices.
\end{abstract}

\section{Introduction}

Parasitic infections of plants, humans, and other animals pose a worldwide problem. For example, more than 650 million people are at risk for gastrointestinal parasitic infection, and about 200 million are actually infected (Pakshir et al., 2009). Hydatidosis is a chronic infection of medical and veterinary importance caused by the larval stage of a cosmopolitan parasitic cestode Echinococcus granulosus (Eckert and Deplazes, 2004; Fasihi Harandi et al., 2012). Clinical manifestation of hydatidosis is characterized by tumor-like growths that occur mostly in the liver and lungs, with varying degrees of infestation of other organs (Abdel-Hafez and Al-Yaman 1989). These growths are usually filled with a watery fluid known as 'hydatid cyst fluid.' The released embryos penetrate the intestinal wall and via the portal system enter mainly into the liver (50-70\%), lungs (20-30\%), or any other organs where the hydatid cysts grow up (Eckert and Deplazes, 2004). Unfortunately, numerous reports 
indicate that hydatidosis incidence has increased in various regions of the world (Eckert et al., 2000). It has been identified as a global public health and economic problem particularly in developing regions including Iraq, which causes serious morbidity and death if left untreated. Measurement of the socio-economic impact of echinococcosis/ hydatidosis represents an important challenge in the involved societies. In humans, the quantifiable items of disease are those connected with preoperative diagnosis, surgical treatment, hospitalization, post surgical examination and drugs (Cook and Zumla, 2003). In many countries, hydatid disease is more prevalent in rural areas where there is close contact between people, dogs, and various domestic animals which act as intermediate hosts (Frider and Larrieu, 2010). Since the mid1970s, significant advances have been made in the chemotherapy of the metacestode stage of Echinococcus. In vitro and in vivo techniques for drug testing are now available, and considerable clinical, pharmacological, and parasitological knowledge has accumulated (Moazeni and Roozitalab, 2010).

Musk was extensively used not only as a fragrance but also for medicinal purposes since ancient times (Takaoka, 2007). Musk is formed from several compounds, the main compound which causes the odour is muscone (3- methylcyclopentadecan-1-one) the active ingredient of musk (Lai,1976) has medicinal properties, Other compounds present in musk include steroids, paraffins, triglycerides, waxes, muco pyridine, other nitrogenous substances and fatty acids ( $\mathrm{Oh}$ et al., 2002; Thevis et al., 2013). Musk is an effective detoxification agent and can be used to reduce pain, inflammation and swelling. It can also be used to treat seizures (Zhu 1989; Cheng et al., 2011). The activity of Musk was studied on the parasitic
Trichomonas vaginalis by Badawy et al. (2014), fungi and bacteria by Saddiq (2014) and AL-Jobori et al.(2014,2016).There are currently three treatment options for hydatid disease, surgery, ultrasound-guided aspiration, and chemotherapy(WHO, 1996). There is clearly a need for drugs that are more effective and easier to administer. Many efforts have been made to discover new antiparasitic compounds from various kinds of sources such as plants, animals and microorganisms. The present study was conducted to evaluate the in vitro effect of Musk on the protoscolices of hydatid cysts.

\section{Materials and Methods}

\section{Parasite Material}

Fresh hydatid cysts were obtained from livers of naturally-infected sheep, which had been slaughtered at local abattoirs in Baghdad province . They were wrapped carefully in clean plastic bags, placed in an ice box, and in the same day of slaughte transported to the Department of Parasitology, University of Baghdad, where protoscoleces were extracted.

\section{Preparation of Protoscolices}

Protoscoleces were extracted according to Smyth (1967). The outer surfaces of the cysts were sterilized with $70 \%$ ethanol before being dissected and it withdrawn fluid sac by syringe $(10 \mathrm{ml})$ then wash the cysts from the inside with a solution of phosphate $(\mathrm{pH}$ of 7.2) and collected in Phosphate buffer solution (PBS) in test tubes, then underwent washing process by centrifuge three times per $3000 \mathrm{c} / \mathrm{m}$ and take the precipitation contain the protoscoleces.

\section{Musk}

Synthetic musk (a Pakistani product) was 
purchased from local Iraqi markets. To determine the scolicidal activity of Musk upon the protoscoleces of hydatid cysts, various concentrations of Musk 25, 50, $100 \%$ and alcohol as control were used for 10, 20, $30,40,50$ and $60 \mathrm{~min}$.

\section{In vitro Scolicidal Effects of Musk}

In this study four concentrations of Musk (0, 25, 50 and $100 \%$ ) were used. A total of 2.5 $\mathrm{mL}$ of each Musk concentration was placed in test tubes, to which a drop of protoscolexrich sediment was added. The contents of the tubes were gently mixed .The tubes were then incubated at $37^{\circ} \mathrm{C}$ for $10,20,30,40,50$ and $60 \mathrm{~min}$. At the end of each incubation time the upper phase was carefully removed so as not to disturb the protoscolices. One milliliter of $0.1 \%$ eosin stain was then added to the remaining settled protoscolices and mixed gently. The upper portion of the solution was discarded after $15 \mathrm{~min}$ of incubation. The remaining pellet of protoscolices was then smeared on a manually scaled glass slide, covered with a cover glass $(24 \times 50 \mathrm{~mm})$, and examined under a light microscope. The percentages of dead protoscolices were determined by counting a minimum of 500 protoscolices. Non treated protoscolices were considered as a control group in each experiment. The experiments were performed in five replications.

\section{Viability Test}

The viability of protoscolices was determined prior to the experiments. A 0.01 $\mathrm{ml}$ solution of pooled protoscolices was transferred over a slide and mixed with 0.01 $\mathrm{ml}$ of $0.1 \%$ aqueous eosin stain, as a vital staining, and was evaluated by low power microscopy after 5 min. Unstained protoscolices were considered as viable while stained protoscolices were considered as non-viable (Smyth and Barrett, 1980). When the percentage of viable protoscolices in the sediment was $95 \%$ or more, they were considered to be appropriate for experiments. The percentage of viable protoscolices (viability rate) was determined by counting a minimum of 100 protoscolices (as a ratio of number of viable protoscolices to total protoscolices).

\section{Statistical Analysis}

The recorded data were statistically analyzed using Statistical Analysis SystemSAS -computer package program (SAS, 2012). The mean values were compared with the least significance difference (LSD) test following (Steel and Torrie, 1980) at 5\% level.

\section{Results and Discussion}

\section{Viability of Protoscolices}

The viability of protoscolices was tested prior to the experiments using $0.1 \%$ aqueous eosin stain. Dead protoscolices absorbed eosin and colored red, but alive protoscolices remained colorless and showed characteristic muscular movements and flame cell activity (evaluated under light microscope).Viability of protoscoleces Untreated protoscoleces remained viable for $60 \mathrm{~min}$ prior to treatment, with no significant differences in viability between 0 and $60 \min (\mathrm{P}<0.05)$.

\section{In vitro Treatment of Protoscoleces}

The viability of protoscoleces was significantly affected when treated with musk. As shown in Figures 1 that different concentrations of musk following different exposure times had potent scolicidal effects against protoscoleces of hydatid cysts.

Musk showed high scolicidal activity 
against protoscolices at all three concentrations tested. While the mortality rate of protoscolices was $6.98 \%$ in the control group (untreated), when protoscolices were exposed to the musk at concentration of $25 \%$, the mortality rate increased to $21.44,34.20,43.00,51.40,79.34$ and $100 \%$ after $10,20,30,40,50$ and 60 minutes, respectively (Table 1). The mortality rates of hydatid cyst protoscolices after exposure to concentration of $50 \%$ of musk were 53.93, 81.36, 97.04 and 100\% after 10, 20, 30, and 40 minutes, respectively (Table 2). The protoscolices treated with concentrations of $100 \%$ started to show a decrease in viability at $10 \mathrm{~min}$ post-treatment, one hundred percent mortality rate was observed after $30 \mathrm{~min}$ of exposure (Table 3). The difference between the scolicidal effect of musk was statistically significant $(\mathrm{P}<0.05)$ for all three concentrations and at various exposure times, comparing to the control group.

Clinical management procedures had evolved over decades without adequate evaluation of important features, such as efficacy, effectiveness, rate of adverse reactions, relapse rate, and cost (Junghanss et al., 2008). To date, many scolicidal agents have been used for inactivation of the hydatid cyst content, but there has been no ideal agent that is both effective and safe (McManus et al., 2003).

A number of drugs are being used and various degrees of success have been claimed. However, the metabolites of certain drugs including benzimidazole, mebendazole, albendazole, and albendazole sulfoxide are potentially toxic in some subjects ( Pawlowski 1997 ) .Also adverse side effects has been reported for $20 \%$ hypertonic saline, $20 \%$ silver nitrate, $0.5 \%$ $1 \%$ cetrimide, ethyl alcohol, and $20 \mathrm{mg} / \mathrm{mL}$ albendazole sulfoxide (Moazeni and
Nazer,2010). Among the most promising advances in the field of drug development is discovering new molecules or novel uses of the already available compounds with known safety and without any side effects (Mathew et al., 2008).Considerable attention to alternative therapies, particularly using natural sources derived compounds for the treatment of diseases has been paid as many studies reviewed the effect of different medical plants on Echinococcus granulosus (Barzinji et al., 2009; Yones et al., 2011;Moazeni and Mohseni,2012 ; Mahmoudvand et al., 2014).

In the present study we investigated the potency of musk concentrations on the protoscolices of hydatid cyst. The results of our study showed that musk has a significant scolicidal activity $(\mathrm{P}<0.05)$ at the concentrations of 25, 50 and $100 \%$ after various exposure times of application (figure 1 and tables 1, 2, 3). In previous studies, we investigated the inhibitory effect of musk at concentrations $25,50,75$, and $100 \%$ on bacteria and fungi (AL-Jobori et al., 2014, 2016).

The inhibitory effect of Musk is due to its content of compounds, the main compound which causes the odour is muscone (3methylcyclopentadecan-1-one) the active ingredient of musk (Lai,1976), has medicinal properties, Other compounds present in musk include steroids, paraffins, triglycerides, waxes, muco pyridine, other nitrogenous substances and fatty acids((Ekwenye and Elegalam, 2005; Thevis et al., 2013). The antimicrobial properties of musk have been established against wide spectra of microbes, including bacteria and fungi, using a variety of experimental methods (Cheng et al., 2011; Saddiq, 2011, 2014). Also revealed motility inhibition of Trichomonas vaginalis trophozoite (Badawy et al., 2014). 
Table.1 Scolicidal Effect of Musk at the Concentration of $25 \%$ Following Various Exposure Times

\begin{tabular}{|c|c|c|c|}
\hline Time (min.) & Live Protoscolices & Dead Protoscolices & Mortality rate (\%) \\
\hline 0 & 2000 & 150 & 6.98 \\
\hline 10 & 1334 & 364 & 21.44 \\
\hline 20 & 1314 & 683 & 34.20 \\
\hline 30 & 1458 & 1100 & 43.00 \\
\hline 40 & 1352 & 1430 & 51.40 \\
\hline 50 & 1180 & 4540 & 79.37 \\
\hline 60 & 0.00 & 2600 & 100.00 \\
\hline L.S.D 0.05 & 115.76 & 113.25 & 7.33 \\
\hline
\end{tabular}

Table.2 Scolicidal Effect of Musk at the Concentration of $50 \%$ Following Various Exposure Times

\begin{tabular}{|l|l|l|l|}
\hline Time (min.) & Live Protoscolices & Dead Protoscolices & Mortality rate (\%) \\
\hline 0 & 2000 & 150 & 6.98 \\
\hline 10 & 1230 & 1440 & 53.93 \\
\hline 20 & 710 & 3100 & 81.36 \\
\hline 30 & 39 & 1280 & 97.04 \\
\hline 40 & 0.00 & 2628 & 100.00 \\
\hline 50 & - & - & - \\
\hline 60 & - & - & - \\
\hline L.S.D. 0.05 & -103.22 & & 100.99 \\
\end{tabular}

Table.3 Scolicidal Effect of Musk at the Concentration of $100 \%$ Following Various Exposure Times

\begin{tabular}{|c|c|c|c|}
\hline Time (min.) & Live Protoscolices & Dead Protoscolices & Mortality rate (\%) \\
\hline 0 & 2000 & 150 & 6.98 \\
\hline 10 & 1420 & 4300 & 75.17 \\
\hline 20 & 1140 & 5520 & 82.88 \\
\hline 30 & 0.00 & 3340 & 100.00 \\
\hline 40 & - & - & - \\
\hline 50 & - & - & - \\
\hline 60 & - & - & - \\
\hline L.S.D. 0.05 & 92.13 & 98.11 & 5.67 \\
\hline
\end{tabular}


Figure.1 In vitro Lethal Effects of Musk against Protoscoleces of Hydatid Cyst at the Various Concentrations Following Various Exposure Times

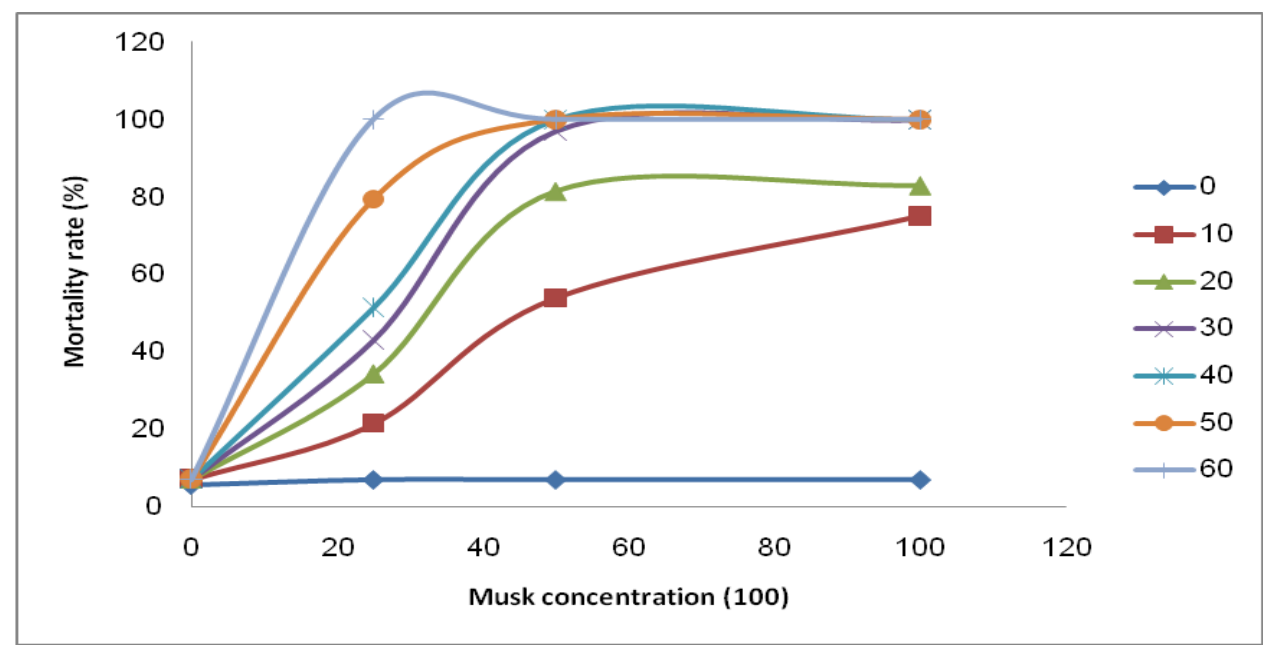

Efficiency of the medicinal plant is referred to its content of many efficient compounds similar to musk content such as flavonoids, peptids and peptide alkaloids and saponin and sugars (lactose, glucose galactose) as well as glycosides and vitamins $\mathrm{A}$ and $\mathrm{C}$ (Abdel-Zaher et al., 2005). They may have target sites, such as inhibitors of protein or DNA synthesis, or within cytoplasmic components, like B-lactam antibiotics (Walker et al., 2004). Suthar et al. (2010) demonstrated that Nigella. sativa oil could inhibit DNA synthesis by inhibiting histone deacetylase (HDAC) enzyme interacting with the chromosomes.

The ideal treatment for patients with hydatid disease should be complete elimination of the parasite and prevent recurrence of the disease with minimal morbidity and mortality. In this study the results showed that the concentration $25 \%$ of musk completely eliminated the parasite after 60 minutes, and the concentration of $50 \%$ completely eliminated the parasite after 40 minutes, whilst the concentration of $100 \%$ completely eliminated the parasite after 30 minutes(figure 1 and tables 1,2,3). This can be a promising source of potent antiprotoscolices. The dose-dependent protoscolicidal effects of musk concentrations seem to be due to their role in breakdown of biological activities of protoscolices through interference with their metabolism.

In conclusion, this in vitro study showed that musk is an effective scolicidal agent. To the best of our knowledge, this is the first report that investigates the scolicidal efficacy of musk concentrations on the protoscolices of hydatid cysts. The results of this study allowed us to suggest that musk is likely source of new compounds that could be used as an effective scolicidal agent .Our data suggest that musk can be a promising source of potent antiprotoscolices.

\section{References}

Abdel-Hafez ,S. ,and Al-Yaman ,F.M. (1989) .Spleen hydatidosis in sheep from North Jordan. Veterinary Parasitology ,30: 191-196.

Abdel-Zaher, A. O.; Salim, S. Y.; Assaf, M. H. and Abdel- Hady, R.H. (2005). Antidiabetic activity and toxicity of Zizyphus spina- christi leaves. 
Ethnopharmacol., 101(1-3):129-138.

AL-Jobori， K.M.M.; AL-Ameed ,AI., \& Witwit, N.M.(2016) In vitro Antifungal Activity of Musk. Didactic Journal of Medicinal Plant Research,1(1):1-6.

AL-Jobori, K.M.M.; AL-Khafagi ,N.A., and Witwit, N.M.(2014). Evaluation of the antagonistic effect of musk on eleven bacterial strains and three types of yeast. Topclass Journal of Microbiology; 2)(1): 1-6.

Badawy, A.F.; Elleboudy, N.A., and Hussein, H.M.(2014). Assessment of in vitro anti-Trichomonas vaginalis activity of deer musk. International Journal of Advanced Research,2 ( 8): 668- 678 .

Barzinji, A.K.R.; Mothana, R.A.,and Nasher, A.K. (2009). Effect of leaf extracts of Dendrosicyos socotrana and Jatropha unicostata on the viability of Echinococcus granulosus protoscoleces. EurAsia J .BioSci .,3: $122-129$.

Cheng, D. H.; Wang, J.; Zeng, N.; Xia, H.L; Fu, Y.; Yan, D.; Zhao, Y.L., and Xiao ,X.H . (2011). Study on drug property differences of shexiang (moschus) and bingpian (borneolum synthcticum) based on analysis of biothermodynamics. J. Tradit. Chin. Med. ,31(1):21-6.

Cook, G.C., and Zumla, A. (2003). Manson's tropical disease.21 st ed. WB Saunders. PP: 1561-63.

Eckert, J.; Conraths, F.J., and Tackmann, K. (2000).Echinococcosis: An emerging or re-emerging zoonosis? Int. J. Parasitol., 30: 1283-1294.

Eckert, j. , and Deplazes, P. (2004).Biological, epidemiological, and clinical aspects of echinococcosis, a zoonosis of increasing concern. Clin. Microbiol. Rev., 17:107- 135.

Ekwenye, U.N. ,and Elegalam, N.N. (2005)
.Antibacterial activity of ginger (Zingiber officinale Roscoe) and (Allium sativum L.) extract on Escherichia coli and Salmonella typhi. J. Molecular and Advance Sci., 1(4):411-416.

Fasihi Harandi, M.; Budke, C.M.,and Rostami ,S.(2012). The Monetary Burden of Cystic Echinococcosis in Iran. PLOS Negl. Trop. Dis., 6:e1915.

Frider, B.,and Larrieu, E. (2010).Treatment of liver hydatidosis: How to treat an asymptomatic carrier? World J. Gastroenterol., 16: 4123- 4129.

Junghanss ,T.; da Silva, A.M.; Horton, J.; Chiodini, P.L., and Brunetti, E. (2008).Clinical management of cystic echinococcosis: state of the art, problems, and perspectives. Am. J. Trop. Med. Hyg., 79:301-311.

Lai, J.H .(1976). Pharmacognosy. Taipei: Chuang-I Press, pp.541.

Mahmoudvand ,H.; Asadi, A.; Fasihi Harandi, M.; Sharififar, F.; Jahanbakhsh, S., and Dezaki ,E.S.(2014). In vitro lethal effects of various extracts of Nigella sativa seed on hydatid cyst protoscoleces. Iran J. Basic Med. Sci. , 17:1001-1006.

Mathew, N.; Misra-Bhattacharya, S.; Vanamail Perumal,V., and Muthuswamy,K.(2008). Antifilarial Lead Molecules Isolated from Trachyspermum ammi. Molecules, 13(9): 2156-2168.

McManus ,D.P.; Zhang, W., Li, J., and Bartley ,P.B.(2003). Echinococcosis. Lancet 362:1295-1304.

Moazeni, M.,and Mohseni, M.(2012). Sumac (Rhus coriaria L.): Scolicidal Activity on Hydatid Cyst Protoscolices. Surgical Science, 3: 452-456.

Moazeni, M., and Nazer, A. (2010).In vitro effectiveness of garlic (Allium sativum) extract on scolices of hydatid 
cyst. World J. Surg., 34: 2677-2681.

Moazeni ,M., and Roozitalab, A.(2010). High scolicidal effect of Zataria multiflora on protoscoleces of hydatid cyst: An in vitro study. Comp. Clin. Pathol., 580: 1068-1073.

Moazeni, M.; Saharkhiz, M..J, and Hosseini, A.A.(2012).In vitro lethal effect of ajowan (Trachyspermum ammi L.) essential oil on hydatid cyst protoscoleces. Vet. Parasitol., 187:203- 208.

Oh, S.R.; Lee, J.P.;Chang, S.Y.; Shin, D.H.; Ahn, K.S.; Min, B.S., and Lee, H.K. (2002). Androstane alkaloids from musk of Moschus moschiferus. Chem. Pharm. Bull., 50:663-664.

Pakshir, K.; Bahaedinie, L.; Rezaei, Z.;Sodaifi ,M. , and Zomorodian, K.(2009). In vitro activity of six antifungal drugs against clinically important Dermatophytes. Jundishapur Journal of Microbiology, 2(4): 158-163.

Pawlowski ,Z.S. (1997) .Critical points in the clinical management of cystic echinococcosis: A revised review. In": Compendium on cystic echinococcosis in Africa and in Middle Eastern countries with special reference to Morocco. F.L. Andersen, H. Ouhelli, M .Kachani (eds.), Brigham Young University Print Services, Provo,pp. 119-135.

Saddiq ,A.A.N. (2011). Potential effect of natural musk and probiotic on some pathogens strain. Int. Res. J. Microbiol.,2(5):146-152.

Saddiq, A.A.N.(2014). Antiagnostic effect of musk and sidr leaves on some of the opportunistic fungi that cause Lung toxicity. Life Science Journal, 11(2s):99-108.

SAS. (2012). Statistical Analysis System, User's Guide. Statistical. Version 9.1th ed.SAS. Inst. Inc. Cary. N.C.
USA.

Smyth, J.D .(1967). Studies on tapeworm physiology. XI. In vitro cultivation of Echinococcus granulosus from protoscolex to the strobilar stage. Parasitology, 57:111-133.

Smyth, J.D., and Barrett, N.J. (1980).Procedures for testing the viability of human hydatid cysts following surgical removal especially after chemotherapy. Trans. R. Soc. Trop. Med. Hyg., 74: 849-852.

Steel , R.G., and Torrie ,J.H. (1980) .Principles and procedures of statistics $.2^{\text {nd }}$ ed. Mc Graw- Hill Book Co., Inc. New York.

Suthar ,M.P.; Patel, P.N.; Shah, T.G., Patel, R.K.(2010). In vitro screening of Nigella sativa seeds for antifungal activity. Inter. J. Pharm. App. Sci., $1: 84-91$

Takaoka, H . (2007). Structure-odour relationships of macrocyclic musks and harmony with the environment. IFEAT International Conference in Budapest, Hungary. , 36-43 in the printed Conference Proceedings

Thevis, M. ; Schänzer, W.; Geyer, H.; Thieme, D.; Grosse,J., and Rauten,C. ( 2013). Traditional Chinese medicine and sports drug testing: identification of natural steroid administration in doping control urine samples resulting from musk (pod) extracts. Br. J. Sports Med.,47(2):109-114.

Walker, M.; Rossignol, J.F.; Torgerson, P., and Hemphil, A.(2004). In vitro effects of nitazoxanide on Echinococcus granulosus protoscolices and metacestodes. J. Antimicrob. Chemother ., 54: 609616.

WHO .(1996). Guidelines for Treatment of Cystic and Alveolar Echinococcosis in Humans. Informal Working Group, pp. 231-242. 
Yones ,D.A.; Taher, G.A., and Ibraheim ,Z.Z. (2011). In Vitro Effects of Some Herbs Used in Egyptian Traditional Medicine on Viability of Protoscolices of Hydatid Cysts. Korean J. Parasitol., 49( 3): 255-263.
Zhu, X.Y. (1989). The pharmacological activities of musk. III. On the mechanisms of its anti-inflammatory activities. Zhongguo Yi Xue Ke Xue Yuan Xue Bao. ,11(1):52-56.

\section{How to cite this article:}

Kamil M. M. AL-Jobori, Azhar Ali Faraj and Noor M. Witwit. 2016. Inhibitory Effectiveness of Musk on Viability of Protoscolices of Hydatid Cysts. Int.J.Curr.Microbiol.App.Sci.5(4): 998-1006. doi: http://dx.doi.org/10.20546/ijcmas.2016.504.114 